\title{
Communication Within Low Income Families and the Management of Asthma
}

Noreen M. Clark ${ }^{\mathrm{a}}$, Moshe J. Levison ${ }^{\mathrm{b}}$, David Evans ${ }^{\mathrm{b}}$, Yvonne Wasilewski ${ }^{\mathrm{b}}$, Charles H. Feldman ${ }^{\mathrm{b}}$ and Robert B. Mellins ${ }^{\mathrm{b}}$

"Department of Health Behavior and Health Foundation, University of Michigan School of Public Health 1420 Washington Heights, Ann Arbor, MI 48109-2029 and ${ }^{b}$ Department of Pediatrics, Columbia University, College of Physicians and Surgeons (U.S.A.)

(Received February 17th, 1989)

(Accepted December 7th, 1989)

\begin{abstract}
This study examines the effects of communication between low income urban parents and children about a chronic disease on the extent to which parent and child effectively manage the illness. Four asthma communication factors were identified by principal component analysis. We found that mothers whose preferred language was Spanish, and families who were not receiving public assistance, communicated more frequently about asthma in general. Spanish speaking mothers and their children communicated more about potential home treatments for asthma, and the more adults in the household the less there was communication about the need for emergency services for asthma. Mothers who preferred to speak Spanish had higher levels of management of the most recent asthma attack. Those whose children communicated with them about asthma in general were higher level managers. Children who influenced their parents' decisions about school attendance, and those whose mothers were more highly educated, had higher levels of
\end{abstract}

N.M. Clark, PhD.

M.I. L evison, PhD

D. Evans, PhD.

Y. Wasilewski, PhD.

C.H. Feldman, MD.

R.B. Mellins, MD asthma attack management. More educated mothers, ones whose children were younger at the time of the onset of asthma, and ones who received public assistance, were more involved "in general" in their child's asthma care.

Keywords: Family communication; Illness communications; Asthma.

\section{Introduction}

Clark and Shope [1] have noted that given the extent and impact of childhood chronic illness, there are few empirical studies of family management of disease, particularly of the role of parent-child communications. While several theoretical discussions exist [2-4], very few investigators have provided data to support or dispel various notions about communication between parent and child related to the child's health problem.

It has been implicit in several recent investigations [5-7] that the management of a child's chronic disease necessitates parent and child collaboration in critical management tasks, with the involvement of the parent decreasing as the child grows older. Nonetheless, there has been no explicit study of how parents and children communicate with each other and influence each other's behavior related to the health condition. 
Findings from the handful of related studies suggest that patterns of communication and influence are complex. Lewis et al. [8] showed that children and parents see a child's health problem differently. They found that children in an adult-free setting chose health services of a different kind and in differing frequency than their parents selected for them. Dielman et al. [9] found that children did not necessarily hold the same health beliefs as their parents nor practice the same behaviors. While the investigators state that parents do have influence on children's behavior, their data suggested that the influence is neither direct nor predictable.

It has been hypothesized that children can have an effect on parents' efforts to give up smoking, but this phenomenon has not been adequately examined. Flay [10] found a decrease in smoking behavior among parents who participated in a quit smoking program with their children. It is not possible to discern from his data, however, whether the behavior change was a direct effect of the program messages or if effects were mediated by the child's influence. Coates et al. [11] reported that eating patterns of family members changed following a school based "heart healthy" program for children. Again, study data do not distinguish influence of children on their parents' behavior from direct effects of the program. Evans et al. [12] found that following a health education program, children with a chronic disease made more efforts to influence their parents' management decisions regarding the disease, and parents reported more frequent consideration of their childrens' opinions. However, the relationship between a child's influence and the management behavior of parent and child was not reported.

The research described in this paper utilized data from a larger investigation by Evans et al. [12]. The study reported here focused on communication between parents and children. We were particularly interested in the extent to which children between 8 and 11 years of age communicated information to parents regarding symptoms of asthma, suggested potential treatment for wheezing episodes, suggested the need for medical services, and advised about school attendance. According to Piaget, children of this age are sufficiently mature to participate with parents in decision making [13]. They also are likely to undertake important management tasks independently of their parents [12].

We wanted to determine the relationships among family social and economic characteristics, communication between parent and child, the child's influence on the parents' asthma decisions, and the levels of attack management by parent and child. We hypothesized that;

(1) A mother's level of education and having fewer financial constraints (not receiving public assistance) would be associated with more family communication and higher levels of attack management by both parents and child; and

(2) Where families had higher levels of communication, and the child influenced the parents' asthma decisions, both parents and child would be higher level managers of asthma attacks.

The hypothesized study relationships are present in Fig. 1.

\section{Methods}

\section{Study population}

Children in the third, fourth, and fifth grades from 12 public elementary schools in two New York City school districts participated in the study. Children were eligible to participate if they had at least three episodes of asthma in the past year as reported by the parent, and had written parental consent.

Letters in both English and Spanish were sent to all parents in each school asking them to indicate if in the past year their children had signs or symptoms generally associated with asthma. Parents who responded were contacted by telephone to verify that their children fit the criteria for participation. 


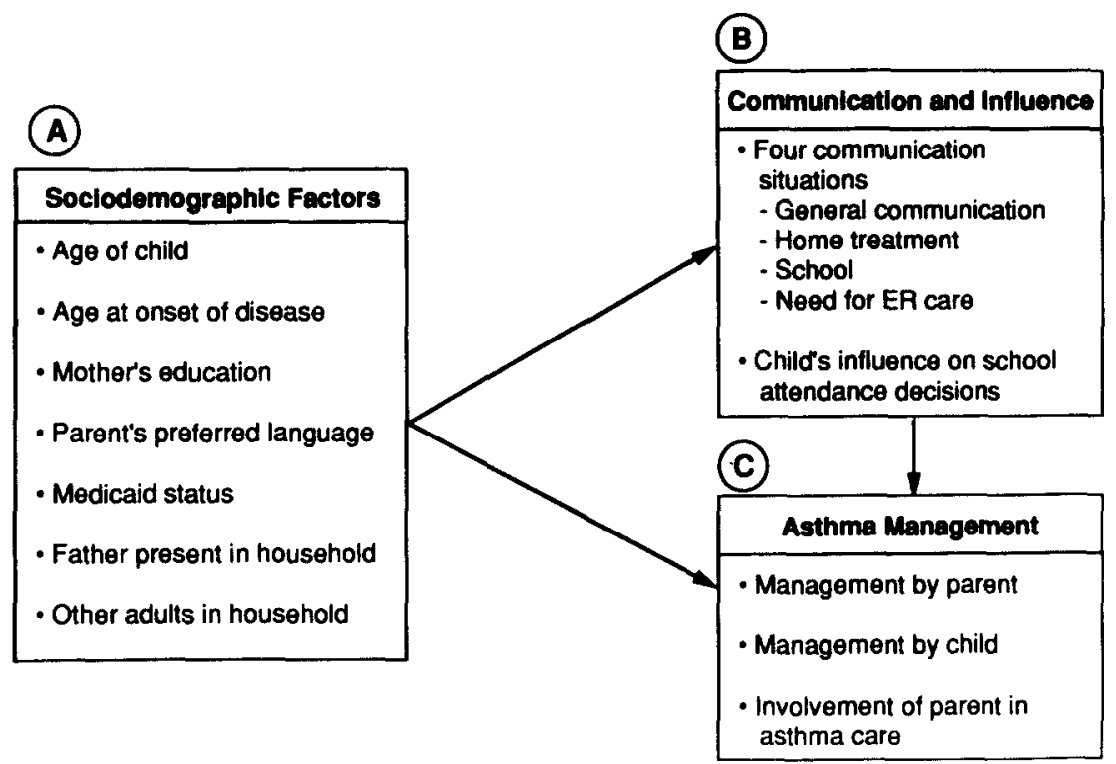

Fig. 1. Hypothesized relationships of study variables.

Contact was made with $76 \%$ of the parents who responded and children of $55 \%$ of those contacted were eligible to participate. Parents of $82 \%$ of this group enrolled their children in the study by completing a telephone interview in English or Spanish and by the child completing a face-to-face interview at school. These procedures resulted in a study population of 239 children from 237 families.

Hospital records were reviewed to determine number of emergency room visits and hospitalizations in the preceding 12 months. School records were reviewed to document a child's grades and school absences. Only data from the baseline interviews of parent and child and baseline data from school and hospital records are reported in this study.

Although this recruitment procedure may have missed some children with asthma, it appears to have yielded a reasonably accurate enumeration of those with the illness in the population studied. The sample represents $5 \%$ of the children in grades three to five, a rate comparable to estimates of asthma in the general population of children made in epide- miologic studies [14]. Although we believe the sample is representative of the families in the 12 schools whose children met criteria, we cannot exclude the possibility that those who participated in the study were more highly motivated than those who did not.

The 239 children were primarily from low income families; $71 \%$ received Medicaid or other forms of public assistance. Seventy percent of the children were Hispanic, $28 \%$ were non-Hispanic blacks and 2\% were non-Hispanic whites. Among many of the Hispanic families, Spanish was the language spoken by the parent even though all study children spoke English. Parents were given the choice of being interviewed in Spanish or English. Those who preferred to be interviewed in Spanish, in the main, were not proficient in English. The mean age of the children was 9.1 years and $59 \%$ were males. The use of emergency health care services in the previous year was low in the sample ( 0.56 per child). Only seven children $(4 \%)$ were hospitalized in the previous year. These data suggest that most children in the sample had mild asthma. 


\section{Measures}

To assess the level of communication by the child, a scale was constructed of items describing four situations common to both parent and child questionnaires: telling mother about (a) the severity of the wheezing episode; (b) a potential remedy for the attack; (c) the need for emergency medical care; and (d) the need to stay home from school.

For each situation, the lowest score was assigned when both parent and child reported that the child did not give information in the situation. Mid-range scores were assigned when there was disagreement about whether or not the child communicated and the highest score was assigned when both said the child did give information. Responses were evaluated for each of the four situation scores and summed to produce a "tell mother" total.

Influence of the child in this study refers to the certainty in the family that the child's communications had impact on the parents' decision to send him* to school or keep him at home. Influence of the child was measured by questionnaire items related to decision making about school attendance. The highest score was assigned when both parent and child said that the child had influence over the decision about school. The next highest score was given when the parent and child did not agree about the child's influence, and the lowest when both agreed that the child did not influence the decision.

The management behavior of parent and child was assessed by the extent to which each independently reported engaging in those behaviors thought to reduce the impact of a child's episodes of wheezing. These included such things as giving or taking medicines, resting, giving or taking adequate liquids, using productive cough, monitoring symptoms, and asking for help. The more behaviors a parent reported, the higher her attack

\footnotetext{
*The masculine pronoun is used in this paper as the majority of children in the study were male.
}

management score. The child's score was computed based on the child's reports.

Five additional behaviors which tap the level of involvement of a parent in asthma control efforts that go beyond the immediate management of symptoms were combined to create an "involvement" scale. These were the extent to which a parent discussed needed modifications in medications with the physician, discussed the child's activity levels with the physician, discussed asthma with the child's teacher, let her child try out activities before setting restrictions, and asked the child to demonstrate asthma control skills before allowing or prohibiting physical activity.

\section{Statistical analysis}

The statistical analysis involved two strategies. The first strategy entailed the choice of communication scores to enter into a multiple regression analysis. To aid us in making this decision, we decided to conduct a principal component analysis (PCA) of the four situation scores. This procedure would enable us to determine which communication items were associated statistically. We considered the PCA a stronger approach than relying solely on the face validity of the situations and summing the four scores. The PCA would show, for example, that if all four situations were equally weighted in the first principal component, while the remaining components accounted for little variance, then the summed score of the four communication situations would be adequate for the regression analysis. If not, the PCA would provide new uncorrelated factors from the four situation scores that would suggest the important dimensions underlying the situation items.

The first factor would be the weighted combination of the original scores that accounted for the most variance in the original scores. The second factor would be the weighted combination of scores which was uncorrelated with the first and which, subject to that constraint, had the next highest proportion of the variance in the original 
Table I. Principal component weights on communication items.

\begin{tabular}{|c|c|c|c|c|}
\hline \multirow[t]{2}{*}{ Communication items } & \multicolumn{4}{|c|}{ Principal component factors } \\
\hline & $\begin{array}{l}\text { I } \\
\text { (general } \\
\text { communication) }\end{array}$ & $\begin{array}{l}\text { II } \\
\text { (home } \\
\text { treatment) }\end{array}$ & $\begin{array}{l}\text { III } \\
\text { (school } \\
\text { communication) }\end{array}$ & $\begin{array}{l}\text { IV } \\
\text { (need for } \\
\text { ER services) }\end{array}$ \\
\hline Need for emergency care & 0.39 & -0.61 & -0.35 & 0.67 \\
\hline Remedies for wheezing & 0.43 & 0.20 & -0.63 & -0.71 \\
\hline Severity of symptoms & 0.36 & 0.77 & 0.21 & 0.56 \\
\hline Need to miss/go to school & 0.40 & -0.31 & 0.82 & -0.40 \\
\hline
\end{tabular}

scores. The third and fourth factors were computed similarly. The PCA was performed with the SPSSX statistical program [15] using the Herman principal component extraction technique.

The PCA showed that the first factor accounted for $40 \%$ of the variance, the second for $23 \%$ and the third for $20 \%$ for a total of $83 \%$ of the variance explained by the three factors. The fourth factor accounted for $17 \%$, or the remaining, variance. These results supported the use of the PCA factors in our further analyses rather than the summed tell mother scores.

Table I presents the principal component weights on the communication items. The four principal component factors can be described as follows. The first factor weights the four scores approximately equally and constitutes communication in general about asthma between the parent and child. We call this the general communication factor.

The second factor put heavy positive weight on telling mother about the severity of an attack, and heavy negative weight on telling mother about the need for emergency care and deciding about school attendance. Telling mother about remedies for the wheezing episode was a lower positive weight. As the second factor was characterized by communication about how the child physically felt and what remedies might be undertaken at home, we call this the home treatment factor.

The third factor put heavy positive weight on telling mother about school and heavy negative weight on telling mother about remedies and the need for emergency care. We labeled this the school communication factor. The fourth factor puts large positive weight on both telling mother about the severity of the episode and the need for emergency care, and put negative weight on telling mother about remedies and school attendance. We called this the need for emergency care (ER) factor.

The second strategy involved a two stage multiple regression analysis. In the first stage of the analysis, the communication factors and the child's influence variable were regressed, in turn, on the sociodemographic variables. This step answered the question: which of the background variables predicted communication and influence? In the second stage,the child's level of asthma management, the parent's level of asthma management, and the parent's level of involvement in the child's asthma care were regressed, in turn, on the communication factors, on the child's influence variable, and on the sociodemographic variables. This step answered the question: which of the communication, influence, and background variables predicted higher levels of management of the illness. Zero order correlations for the variables included in the regressions are presented in Table II.

\section{Findings}

The relationship between sociodemographic variables and communication

Table III presents the results of the first 


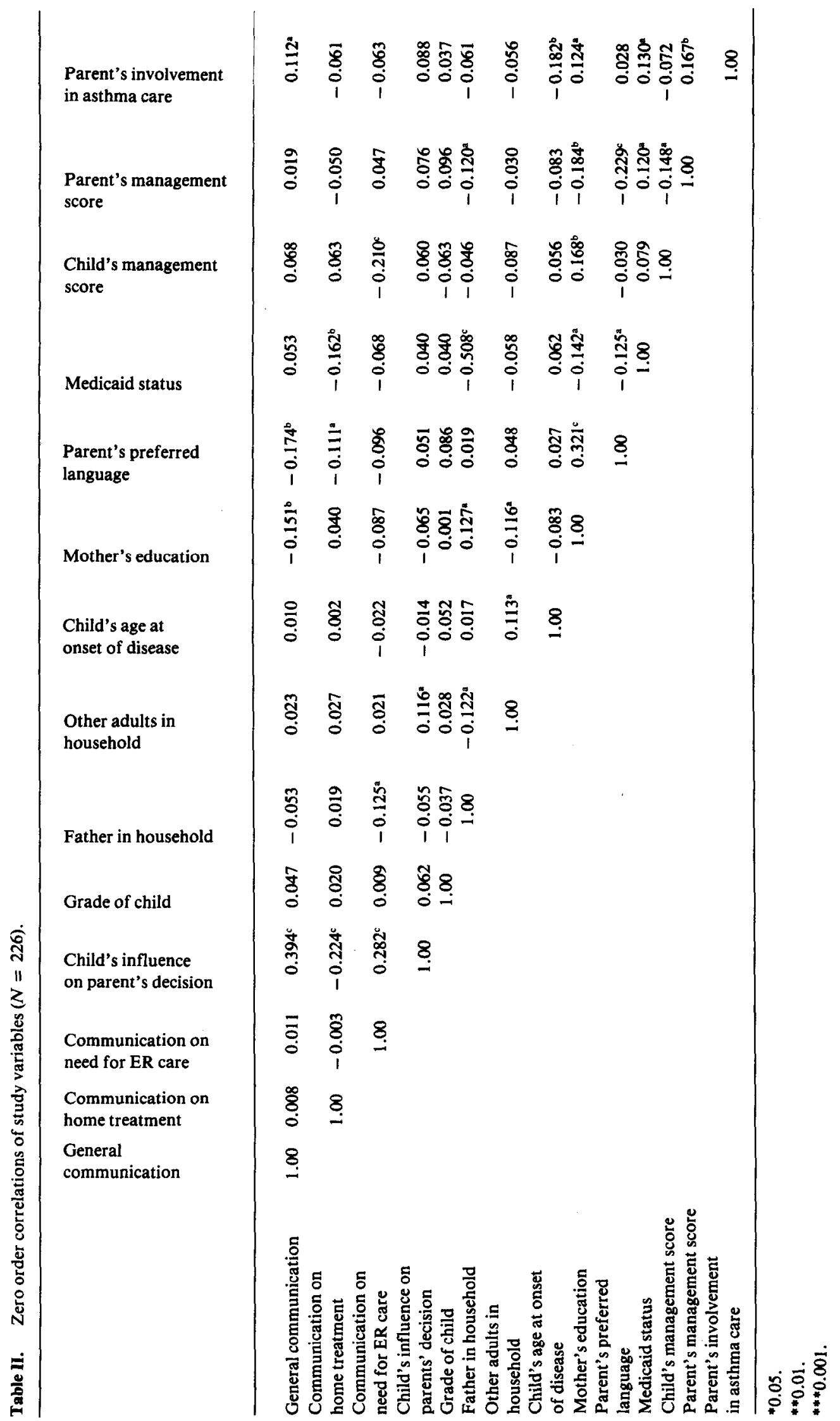


Table III. Principal component analysis (PCA) communication factors regressed on sociodemographic variables beta weights ${ }^{\mathrm{a}}$.

\begin{tabular}{|c|c|c|c|c|}
\hline & \multicolumn{4}{|c|}{ PCA communication factors } \\
\hline & $\begin{array}{l}\text { General } \\
\text { communication }\end{array}$ & $\begin{array}{l}\text { Home } \\
\text { treatment }\end{array}$ & $\begin{array}{l}\text { School } \\
\text { communication }\end{array}$ & $\begin{array}{l}\text { Need for } \\
\text { ER care }\end{array}$ \\
\hline $\begin{array}{l}\text { Mother prefers Spanish language } \\
\text { Mother's level of education }\end{array}$ & 0.174 & 0.134 & & \\
\hline $\begin{array}{l}\text { Father present in home } \\
\text { Other adults in home } \\
\text { Child's age at onset of asthma } \\
\text { Child's grade in school }\end{array}$ & & & & -0.140 \\
\hline Medicaid status & & -0.178 & & \\
\hline Mult. $R$ & 0.174 & 0.209 & 0.140 & \\
\hline$R^{2}$ & 0.030 & 0.044 & 0.020 & \\
\hline Standard error & 0.992 & 0.991 & 1.010 & \\
\hline$F$ & 7.031 & 5.094 & 4.476 & \\
\hline DF Reg/DF residual & $1 / 224$ & $2 / 223$ & $1 / 224$ & \\
\hline$P$ & 0.0086 & 0.0069 & 0.0355 & \\
\hline
\end{tabular}

anly values significant at $P<0.05$ are presented.

Table IV. Management of an asthma attack by parent and child and parent's involvement in asthma care regressed on the PCA communication factors and sociodemographic variables ${ }^{\mathrm{a}}$.

\begin{tabular}{|c|c|c|c|}
\hline & $\begin{array}{l}\text { Management } \\
\text { by child }\end{array}$ & $\begin{array}{l}\text { Management } \\
\text { by parent }\end{array}$ & $\begin{array}{l}\text { Parent's involvement } \\
\text { in asthma care }\end{array}$ \\
\hline \multicolumn{4}{|l|}{ Communication factors } \\
\hline General communication & & & 0.128 \\
\hline \multicolumn{4}{|l|}{ Home treatment } \\
\hline School communication & -0.234 & & \\
\hline \multicolumn{4}{|l|}{ Need for ER care } \\
\hline \multicolumn{4}{|l|}{ Child's influence in school attendance } \\
\hline Mother prefers Spanish language & & 0.229 & \\
\hline Mother's level of education & 0.156 & & 0.151 \\
\hline \multicolumn{4}{|l|}{ Father present in home } \\
\hline Child's age at onset of asthma & & & -0.181 \\
\hline \multicolumn{4}{|l|}{ Child's grade in school } \\
\hline Medicaid status & & & 0.155 \\
\hline Mult. $R$ & 0.289 & 0.229 & 0.294 \\
\hline$R^{2}$ & 0.083 & 0.053 & 0.086 \\
\hline Standard error & 1.228 & 1.493 & 1.158 \\
\hline$F$ & 6.740 & 12.445 & 5.212 \\
\hline DF Reg/DF residual & $3 / 222$ & $1 / 224$ & $4 / 221$ \\
\hline$P$ & 0.0002 & 0.0005 & 0.0005 \\
\hline
\end{tabular}

Only values significant at $P<0.05$ are presented. 
stage of the regression analysis. As can be seen in Table III a mother's preferred language predicted the general communication factor. If a mother preferred to respond to the study interview in Spanish, she and her child were much more likely to communicate in general about asthma. The analysis also showed that responding in Spanish and not being on Medicaid both predicted the home treatment factor, that is, communicating about the severity of the wheezing and the potential remedies for treating it. None of the background variables predicted the school communication factor. The number of other adults in the home predicted communication about the need for ER services. The fewer the number of adults in the home the more the parent and child communicated about the severity of the episode and the need for emergency care.

The relationship between sociodemographic variables communication and management of asthma

Table IV presents the results of the second stage of regression analysis. When the child and his parent communicated about school,

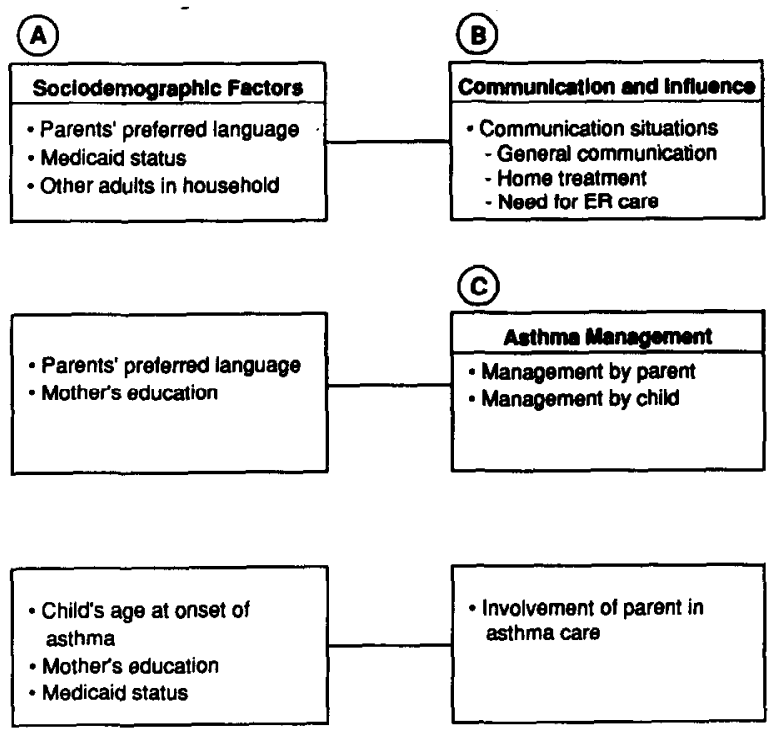

Fig. 2. Sociodemographic factors predicting communication and asthma management.

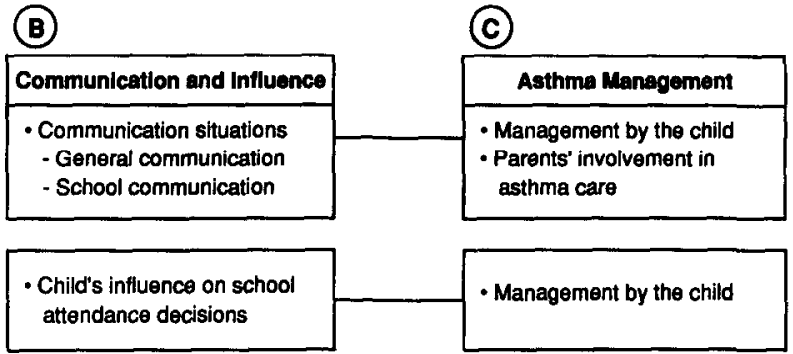

Fig. 3. Communication and influence factors predicting asthma management.

the level of the child's management of the most recent wheezing episode was lower. When the child exerted more influence over decisions about school attendance, and when his mother had a higher level of formal education, the child's level of management of the most recent wheezing episode was higher.

The only predictor of higher levels of asthma management by the mother was her preferred language. Parents who preferred Spanish used more steps to treat asthma episodes than parents who preferred English. A higher level of general involvement in the child's asthma care was predicted by a higher level of education, being on Medicaid, an earlier age of onset of asthma in the child, and a higher general level of communication about asthma. Figures 2 and 3 present the predictive relationships of the study variables identified in the regression analyses.

\section{Discussion}

These data suggest that communication between parent and child about asthma was greater in families where the parent's preferred language is Spanish. Children of these parents tell them more about asthma in general and make suggestions to the adults about ways to treat the wheezing episode. These higher levels of communication may be an aspect of culture. In a recent review, Westberg [16] has commented on the centrality of the family in Hispanic culture, and Levenson et al. [17] found that adolescent Hispanics 
more than other teens wished to have parents included in discussions of their health problems. It may also be that these Spanish speaking parents rely morc on their children for information from the English speaking community. All of the study children speak English, and the parents, regardless of their preferred language, must operate in a larger society dominated by English.

Spanish speaking parents scored higher on the attack management index. Again, the fact that these mothers operate in a environment that is somewhat unfamiliar may cause them to attempt more management activities in order to exert control over the situation. It is interesting to note that it was the home treatment communication factor that was predicted by speaking Spanish, that is, discussion about the severity of wheezing and remedies for it.

This suggests that these parents and their children interact more frequently regarding solutions available at home. This finding is supported by the work of Anderson et al. [18] who have discussed the tendency among Hispanic family members to first seek curative measures within the family. Again, language facility may be a factor. Using hospital or physician services brings parents into a complex medical system that may be difficult to handle given language constraints.

Cost of medical services may also be relevant. The fact that Medicaid status (not receiving assistance) was also associated with this communication component leads us to speculate that going outside the home for solutions to the attack may be more costly for these families than for those receiving aid. As discussed, the study sample was comprised of low income families. Several investigators $[19,20]$ have suggested that those below and just above the poverty line are likely to have inadqueate insurance coverage if any. Confronting a costly and English speaking health care system may motivate these families to consider a variety of alternatives at home before contemplating emergency services.

Lending support to this notion is the find- ing that those mothers most involved in their children's asthma care (discussing medicines and activity levels with physicians, conferring with teachers, etc.) were receiving Medicaid assistance regardless of the language they preferred. Being sure that clinic visits will be paid for makes using the health care system a more immediate option. These mothers were also more highly educated and, perhaps as a result, more prepared to interact both with professionals and their children, and more sophisticated in their decision making about their children's activities. In addition, more involved mothers were those whose children were younger in age at the onset of the disease. There is little doubt that living longer with the disease makes one more knowledgeable about sources of information and services.

Increased communication about wheezing severity and emergency services was associated with having fewer adults in the household. This suggests that parent and child have fewer individuals to turn to in the face of an asthma attack and in that sense, fewer sources of support for care at home.

Finally, the children who managed their disease more actively were those who were more influential with their parents and whose mothers were more highly educated. As noted above, these mothers may be more sophisticated in their dealing with the health care system and this sophistication may extend to accepting a child's judgments about his own condition.

\section{Conclusions}

There are several implications for health counselors and educators in the results of this research. These are summarized in Table V. Study findings show that low income urban parents whose preferred language is Spanish are more likely to be active asthma managers and to be given information by their children about asthma in general and, espeically, regarding remedies to undertake at home in the face of symptoms of asthma. 
Table V. Practice implications.

- Children of Spanish speaking parents should receive direct education on asthma management and be encouraged to share information with their parents

- Education and counseling should build on and reinforce intra-family communication patterns in Hispanic families

- Families where the parent uses Spanish for most communication may need to be helped to identify asthma episodes requiring medical care from those treatable at home

- Mothers with lower educational levels need to be encouraged to discuss asthma with their children and listen to the child's point of view

- Less well educated mothers need to encourage their children to become self-managers of asthma

These results suggest that the children constitute an important target for education about asthma management as the family's window on the English speaking world. Children of Spanish speaking parents provide information within the family that has bearing on the parent's management activities. Clinicians and educators should reinforce the intra-family communication patterns apparent in Hispanic families [16] and encourage additional at home management activities to be undertaken by the child himself. Further, professionals need to encourage at-home treatment while at the same time underscoring for these families the situations and processes entailed when medical care is needed. Given the serious nature of asthma, the families must not fail to communicate with each other about the possibility of emergency service when it is warranted.

As might be expected, regardless of race or language preference, children with more highly educated mothers are more likely to be active self-managers of asthma, and to be influential in family decisions. Clinicians and educators, no doubt, would want to reinforce the self-management activities undertaken by these children and encourage their taking over more tasks as their age allows. Special encouragement may be needed for less well educated mothers and for their children to enable them to discuss asthma more fully within the family and to better understand how they can help each other improve as asthma managers. These children appear to need special help to develop as independent managers of their own disease.

\section{Acknowledgment}

The authors are grateful to Dr. Bruce Levin for his valuable assistance in the preparation of this manuscript. The work described in this paper was supported in part by grant number 1-R18-HL-28907 from the Lung Division, National Heart, Lung, and Blood Institute, and a gift from the Spunk Fund.

\section{References}

1 Clark NM, Shope JT: The current knowledge base for health education programs for chronically ill children. Adv Health Educ Promotion 1986; 1: 397-434.

2 Hobbs N, Perrin JM: Issues in the Care of Children with Chronic Illness. San Francisco: Jossey-Bass, 1985.

3 Hobbs N, Perrin JM, Ireys HT: Chronically Ill Children and Their Families. San Francisco: Jossey-Bass, 1985.

4 Karpel MA, Strauss ES: Family Evaluation. New York: Gardner Press, 1983.

5 Clark NM, Feldman CH, Evans D, Duzey O, Levison MJ, Wasilewski Y, Kaplan D, Rips J, Mellins RB: Managing better: children, parents, and asthma. Patient Educ Couns 1986; 8: 27-38.

6 Creer T: Living with asthma: Replication and extensions. Health Educ Q 1987; 14: 319-332.

7 McNabb W, Wilson-Pessano S, Hughes G, Scamagas P: Self-management education of children with asthma: AIR WISE. Am J Public Health 1985; 75: 1219-1220.

8 Lewis CE, Lewis MA, Lorimer A, Palmer BB: Childinitiated care: The use of school nursing services by children in an "adult-free" system. Pediatrics 1977; 60: 499 -507 .

9 Dielman TE, Leech S, Becker MH, Rosenstock IM, Horvath WJ, Radius SM: Parental and child health beliefs and behavior. Health Educ Q 1982; 9: 60-77.

10 Flay BR: Psychosocial approaches to smoking prevention: a review of findings. Health Psychol 1985; 4: 449-488. 
11 Coates TJ, Jeffrey RW, Slinkard LA: Heart healthy eating and exercise: introducing and maintaining changes in health behaviors. Am J Public Health 1981; 71: 1523.

12 Evans D, Clark NM, Feldman CH, Rips J, Kaplan D, Levison MJ, Wasilewski Y, Levin B, Mellins RB: A school health education program for children with asthma aged 8-11 years. Health Educ Q 1987; 14: 267280.

13 Schwebel M, Raph J. Piaget in the Classroom. New York: Basic Books, 1973.

14 National Institute of Allergy and Infectious Disease: Asthma and Other Allergic Diseases: NIAID Task Force Report, NIH Publication No. 79-397, 1979.
15 SPSSX User's Guide, 2nd edn. Chapter 27, pp. 715-730. Chicago: SPSS, 1986.

16 Westberg J: Patient education for Hispanic Americans. Patient Educ Couns 1989; 13: 143-160.

17 Levenson PM, Pfefferbaum BJ, Copeland DR, Silberberg U: J Adolescent Health Care 1982; 1: 9-13.

18 Andersen RM, Giachello AL, Aday L: Access of Hispanics to health care and cuts in services: a state-of-the-art overview. Public Health Rep 1986; 101: 238-262.

19 Farlcy PJ: Who are the underinsured? Milbank Mem Fund Q/Health Soc 1985; 63: 475-503.

20 National Center for Health Statistics: Advancedata 1987; 139: 1-8. 